\title{
Catalytic and adsorption properties of materials based on natural alumosilicate modified with carbon
}

\author{
Mikhail Fidchenko ${ }^{1 *}$, Marina Alekhina ${ }^{1}$, Anastasia Beznosyuk ${ }^{1}$, and Alika Varnavskaya $^{1}$ \\ ${ }^{1}$ D.Mendeleev University of Chemical Technology of Russia, Moscow, Russia
}

\begin{abstract}
Research of adsorption and catalytic properties of carbon mineral materials made of natural alumosilicates modified by carbon of organic substances for water purification from various organic impurities
\end{abstract}

\section{Introduction}

One of the most used and effective adsorbents and catalyst components for water purification from organic impurities is activated carbon (AC) but activated carbons are expensive materials. Along with $\mathrm{AC}$ one of the most used materials are carburized materials made of cheaper primary products and production waste [1-2].

Natural clays that contain transition metals can be used as a porous matrix for this type of adsorbents and catalysts. The advantages of using natural clays over other materials are availability, cheapness, availability of sufficient raw materials, non-toxicity. Various carbonic materials can be used as modifiers. One of the carbon materials that can be used as a main product are used car tires [3].

The purpose of this research work was the synthesis of carbon-mineral materials based on natural montmorillonite clays containing iron and tire crumbs, as well as the study of their adsorption and catalytic properties.

\section{Experimental}

A sample of montmorillonite clay with the iron content 7,8 mass $\%$ was grinded, sifted and fractions sized $0.25-1 \mathrm{~mm}$ were selected. Tire crumbs (product of the car tires recycling) were used as a carbon source. A mixture of clay and tire crumbs was granulated; the resulting granules were subjected to airless pyrolysis at $350-800^{\circ} \mathrm{C}$.

The elemental composition of specimens was determined by X-ray fluorescence using the X-MAX INCA ENERGY attachment (Oxford Instruments, Great Britain) on a JEOL JSM-6510 LV electron microscope (JEOL, Japan) at the D. Mendeleev Center of Collective Use.

To determine the structural and energy characteristics of aerogel samples, the nitrogen adsorption isotherms were recorded at $77 \mathrm{~K}$ with a Nova $1200 \mathrm{e}$ volumetric installation (Quantachrome, the United States). Before isotherms were taken, the samples were degassed at $250^{\circ} \mathrm{C}$ and a residual pressure of $10^{-3} \mathrm{~mm} \mathrm{Hg}$ within $4 \mathrm{~h}$. The specific surface area $\mathrm{S}_{\mathrm{sp}}$ of the samples was calculated using the BET equation, and the volume of the adsorption space of micropores and characteristic adsorption energy $\left(\mathrm{W}_{0}, \mathrm{E}_{0}\right)$ were calculated using the DubininRadushkevich equation. The total sorption volume of meso- and micropores, $\mathrm{V}_{\mathrm{s}}$, was determined from the nitrogen adsorption isotherm at a relative pressure of 0.995 . The average diameter of mesopores $\left(D_{\text {meso }}\right)$ was determined by the BJH method from the desorption branch of the isotherm.

Isotherms of water vapor adsorption on all carbonmineral material $(\mathrm{CMM})$ samples at $20^{\circ} \mathrm{C}$ were obtained by the desiccator method. The equilibrium value of water vapor adsorption, $a_{\mathrm{H} 2 \mathrm{O}}$ in $(\mathrm{g} / 100 \mathrm{~g})$ of the sample was calculated by the formula:

$$
a_{H_{2} \circ}=\frac{m_{1}-m_{2}}{m_{2}-m_{3}} \cdot 100
$$

where: $\mathrm{m}_{1}$ is the mass of the bottle with the material sample after the end of the sorption process, $(\mathrm{g}) ; \mathrm{m}_{2}$ - mass of a bottle with a sample of material after drying the sample to constant mass, $(\mathrm{g}) ; \mathrm{m}_{3}$ is the mass of the bottle dried to constant mass, $(\mathrm{g})$.

The adsorption of nonionic surfactants from solutions on the obtained adsorbents was studied using the example of neonol AF9-10. Weighed portions of pre-dried adsorbents of different weights $(0.125-1.6 \mathrm{~g} / \mathrm{L})$ were added to model solutions of neonol AF9-10 with a concentration of $50 \mathrm{mg} / \mathrm{L}$. The flasks were kept in a dark place and their contents were shaken for 7 days. The equilibration time was determined in preliminary experiments. After shaking, the sample was filtered, the solution was centrifuged and analyzed. The concentration of neonol in the initial and equilibrium solutions was determined using a Specord M40 spectrophotometer at $272 \mathrm{~nm}$. The amount of excess adsorption of neonol was calculated by the formula:

$$
\Gamma=\frac{\left(C_{0}-c_{p}\right) \cdot V}{g}
$$

where $\Gamma$ is the amount of excess adsorption of neonol, $(\mathrm{mg} / \mathrm{g}) ; \mathrm{c}_{0}$ - concentration of the initial solution, $(\mathrm{mg} / \mathrm{l}) ; \mathrm{c}_{\mathrm{p}}$ - equilibrium solution concentration, $(\mathrm{mg} / \mathrm{l}) ; \mathrm{V}$ is the volume of the solution, (l); $\mathrm{g}$ is the mass of the adsorbent, (g). The determining error was within $2 \%$.

The catalytic properties of the samples were studied in the reactions of decomposition of hydrogen peroxide and

*Corresponding author: fidchenkomm@mail.ru 
destructive oxidation of neonol AF9-10 in an aqueous solution.

Decomposition of $\mathrm{H}_{2} \mathrm{O}_{2}$ was performed in the static reactor with a stirrer. Sample of a sorbent weighed $0.1 \mathrm{~g}$ was placed into the reactor, where a solution of $\mathrm{H}_{2} \mathrm{O}_{2}$ with a concentration of $150 \mathrm{mg} / \mathrm{l}$ with a volume of $50 \mathrm{ml}$ was injected. Process temperature was at $70^{\circ} \mathrm{C}$, time of contact -1 hour. After phase separation, the residual concentration of hydrogen peroxide was determined by iodometric titration.

The degree of decomposition of hydrogen peroxide, $\alpha$ (\%) was determined by the formula:

$$
\mathrm{a}=\frac{C_{\text {ini } \mathrm{H} 2 \mathrm{O}}-C_{\text {res } \mathrm{H} 2 \mathrm{O}}}{C_{\text {ini } \mathrm{H} 2 \mathrm{O}}} \times 100
$$

Neonol was oxidized with hydrogen peroxide at $70^{\circ} \mathrm{C}$ in the dynamic mode. The CMM sample was placed in a jacketed reactor, through which a model solution containing neonol and hydrogen peroxide was passed at a flow rate of $0.47 \mathrm{l} / \mathrm{h}$. The height of the sample layer was 3 $\mathrm{cm}$, the $\mathrm{pH}$ of the solution was 10 , the initial concentration of $\mathrm{H}_{2} \mathrm{O}_{2}$ was $100 \mathrm{mg} / \mathrm{l}$ and of neonol was $50 \mathrm{mg} / \mathrm{l}$ ). At the outlet, samples of the solution were selected and the content of $\mathrm{H}_{2} \mathrm{O}_{2}$ and neonol AF9-10 was determined.

\section{Results and discussion}

The textural characteristics of the samples pyrolyzed at temperatures of $500^{\circ} \mathrm{C}$ and $750^{\circ} \mathrm{C}$ are presented in Table. 1 .

The obtained materials had a mesoporous structure. The results showed that an increase in the pyrolysis temperature led to a decrease in the values of the specific surface area and volume of micropores. The total sorption volume of meso- and micropores $\left(\mathrm{V}_{\mathrm{s}}\right)$ increased, while the average diameter of mesopores decreased. The change in the texture characteristics is associated with the filling of the montmorillonite matrix of the CMM with carbon. These results were confirmed by X-ray phase analysis (fig. $1 \mathrm{a}, \mathrm{b}$ ).

The diffraction patterns clearly show an increase in the number of peaks corresponding to graphite-like deposits on the surface of the CMM sample pyrolyzed at $800^{\circ} \mathrm{C}$. Depending on the pyrolysis temperature, the carbon content on the montmorillonite surface, as shown by elemental analysis, ranged from 17 to 48 mass \%, which can be differently affect the adsorption and catalytic properties of CMM. The iron content in the pyrolyzed samples was 2.5-4.0 mass \%.

Isotherms of water vapor adsorption on CMM samples at $20^{\circ} \mathrm{C}$ are shown in Fig. 2.

Table 1. Texture characteristics of CMM samples.

\begin{tabular}{|c|c|c|c|c|c|}
\hline \multirow[t]{2}{*}{$\begin{array}{l}\text { Pyrolysis } \\
\text { temp. } \\
\left({ }^{\circ} \mathrm{C}\right)\end{array}$} & \multirow{2}{*}{$\begin{array}{c}\text { BET } \\
\text { Specific } \\
\text { surface } \\
\text { area } \mathbf{S}_{\mathrm{sp}} \\
\left(\mathrm{m}^{2} / \mathrm{g}\right)\end{array}$} & \multicolumn{2}{|c|}{$\begin{array}{c}\text { Parameters of the } \\
\text { Dubinin- } \\
\text { Radushkevich } \\
\text { equation }\end{array}$} & \multirow[t]{2}{*}{$\begin{array}{c}V_{\mathrm{s}} \\
\left(\mathrm{cm}^{3} / \mathrm{g}\right)\end{array}$} & \multirow[t]{2}{*}{$\begin{array}{l}D_{\text {meso }} \\
\text { BJH } \\
(\mathrm{nm})\end{array}$} \\
\hline & & $\begin{array}{c}\mathrm{W}_{0} \\
\left(\mathrm{~cm}^{3} / \mathrm{g}\right)\end{array}$ & $\begin{array}{c}\mathbf{E}_{0} \\
(\mathrm{~kJ} / \mathrm{mol})\end{array}$ & & \\
\hline 500 & 61,7 & 0,03 & 11,9 & 0,05 & 27,9 \\
\hline 750 & 15,6 & 0,01 & 14,1 & 0,35 & 4,0 \\
\hline
\end{tabular}

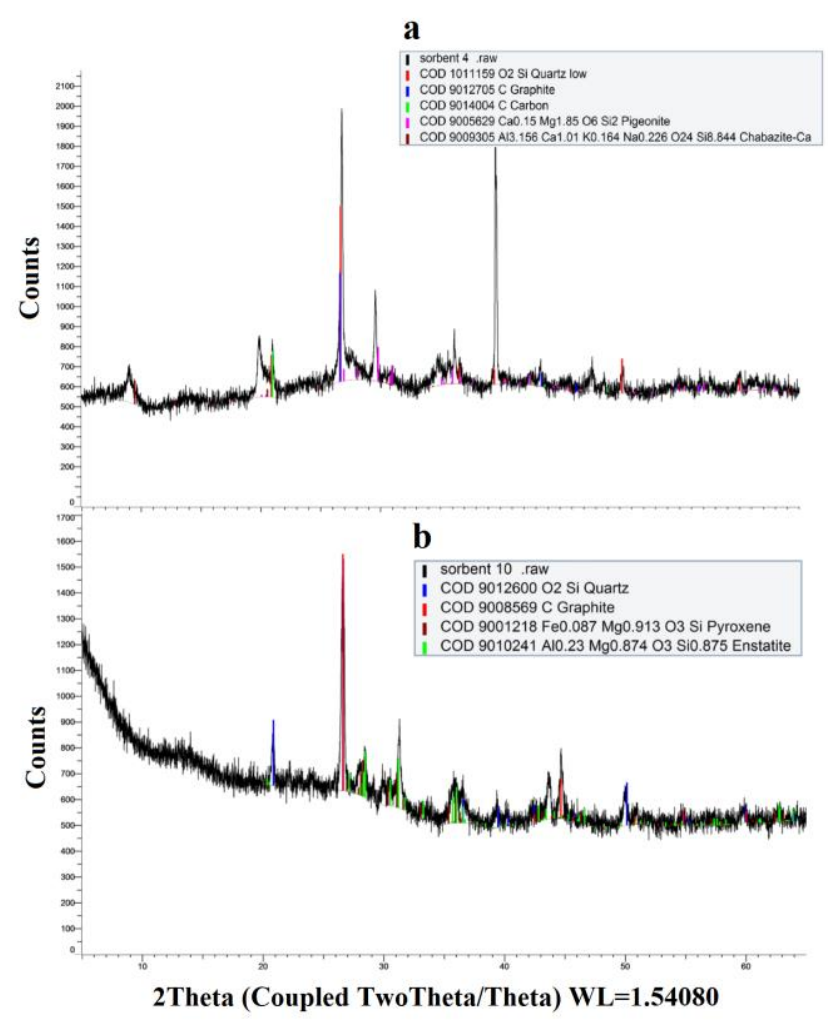

Fig. 1. Diffraction patterns of CMM samples pyrolyzed at 500 (a) and $800^{\circ} \mathrm{C}(\mathrm{b})$.

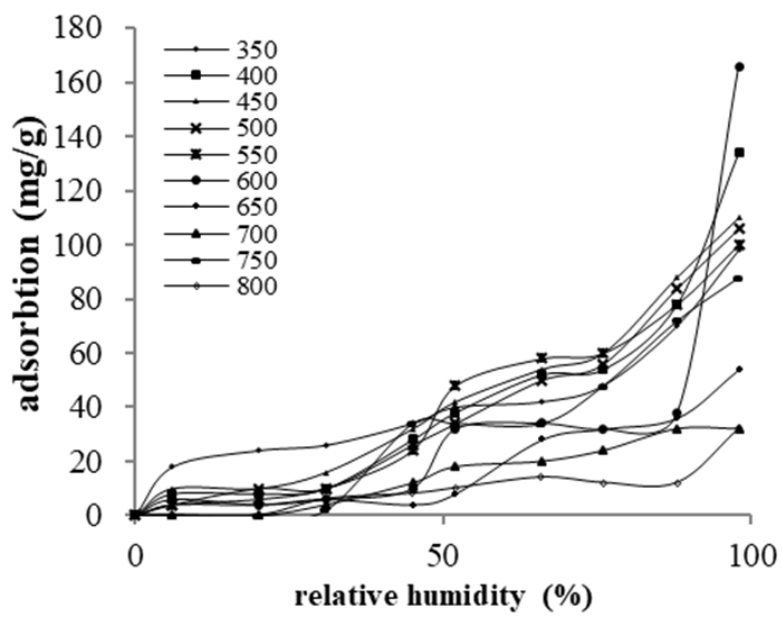

Fig. 2 Isotherms of water vapor adsorption at $20^{\circ} \mathrm{C}$ on samples of carbon-mineral material pyrolyzed at different temperatures.

The CMM samples showed a general decrease in the amount of adsorbed water with an increase in the pyrolysis temperature during the synthesis of the material, which is associated with a more complete coverage of the inner surface of montmorillonite with a carbon layer as a result of carbonization. The maximum value of adsorption attained on the sample of the initial montmorillonite was $264 \mathrm{mg} / \mathrm{g}$. This is almost 1.5 times higher than the maximum value obtained for pyrolyzed CMMs. The presence of a convex region on the isotherms of water vapor adsorption by the samples (Fig. 3) suggests that in the region of low relative pressures, adsorption occurs mainly on the primary adsorption centers, which are metal cations and protons of hydroxyl groups of montmorillonite. If we assume that they are energetically 
homogeneous, then the Langmuir equation can be used to describe the initial sections of water vapor adsorption isotherms by pyrolyzed samples and to determine the number of primary adsorption centers (PAC). Fig. 4 shows the dependence of the number of PACs calculated by the Langmuir equation $\left(a_{\mathrm{m}},(\mathrm{mg} / \mathrm{g})\right)$ on the pyrolysis temperature of the samples.

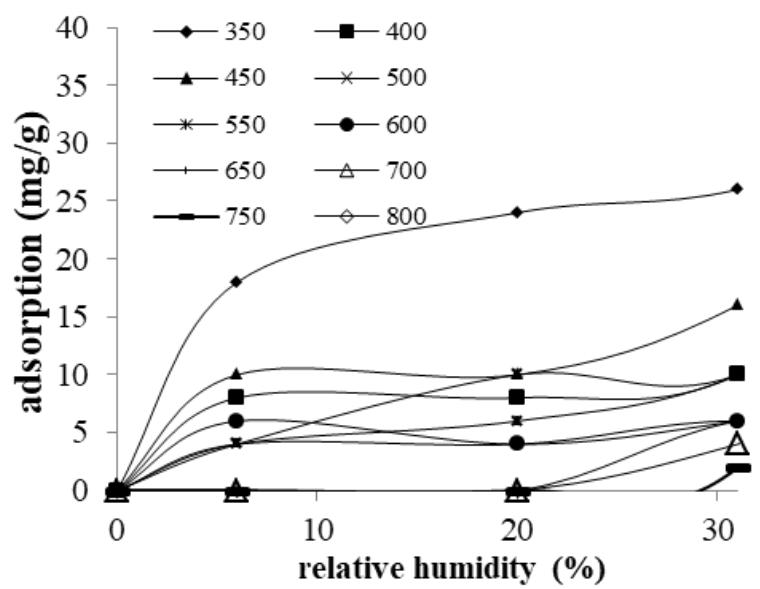

Fig. 3. The initial sections of water vapor adsorption isotherms by samples pyrolyzed at different temperatures

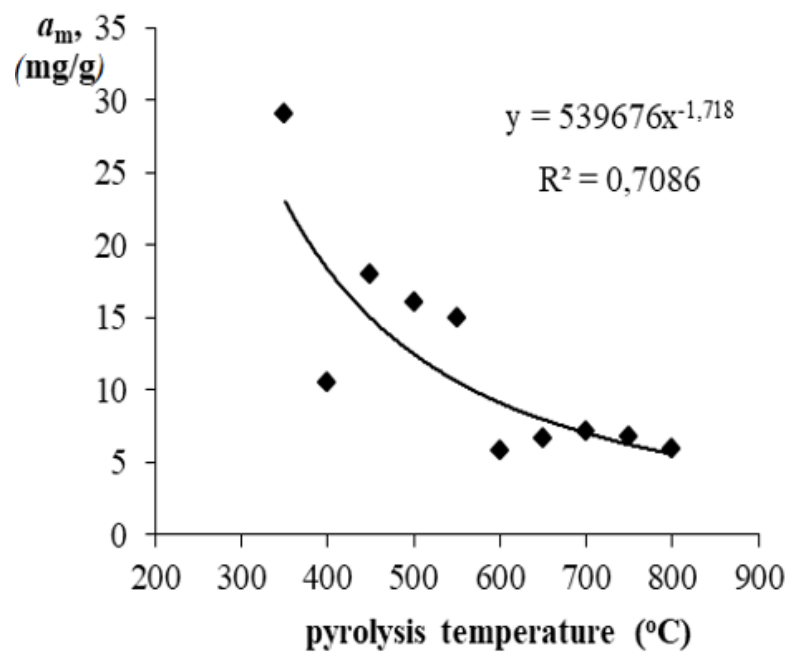

Fig. 4 Dependence of the number of surface adsorption centers of water vapor on the surface of samples of carbon-mineral material depending on the pyrolysis temperature.

The value of $a_{\mathrm{m}}$ decreases with an increase in the pyrolysis temperature of material granules, which indicates that a significant part of PAC is destroyed or screened by carbon during the carbonization of the material.

Fig. 5 shows the isotherm of excessive adsorption of neonol AF9-10 from aqueous solutions at $20^{\circ} \mathrm{C}$ on a CMM sample pyrolyzed at $750^{\circ} \mathrm{C}$. Here, for comparison, the isotherm of adsorption of neonol AF9-10 at $20^{\circ} \mathrm{C}$ on active carbon F-300 is shown [4].

As can be seen from the figure, the CMM sample is somewhat inferior in capacity to the activated carbon F300 , but it can be used for the adsorptive purification of wastewater from neonol AF9-10 and other surfactants.
The CMM samples were tested in the catalytic decomposition of hydrogen peroxide. The results are presented in Table. 2 .

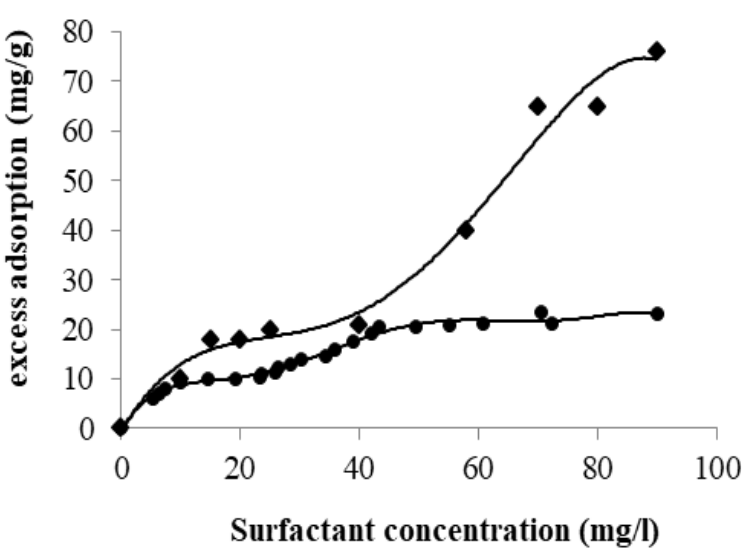

Fig. 5. Isotherms of excessive adsorption of neonol AF9-10 from aqueous solutions at $20^{\circ} \mathrm{C}$ on a carbon-mineral adsorbent obtained at a pyrolysis temperature of $750^{\circ} \mathrm{C}$ and activated carbon F-300 [4].

Table 2. Results of experiments on the decomposition of hydrogen peroxide on CMM.

\begin{tabular}{|c|c|c|c|}
\hline $\begin{array}{c}\text { Sample } \\
\text { pyrolysis } \\
\text { temperatur } \\
\mathbf{e}\left({ }^{\circ} \mathbf{C}\right)\end{array}$ & $\begin{array}{c}\text { Solution } \\
\text { volume } \\
\mathbf{N a}_{2} \mathbf{S}_{2} \mathbf{O}_{3}(\mathbf{m l})\end{array}$ & $\begin{array}{c}\text { Residual } \\
\text { quantity } \\
\mathbf{H}_{2} \mathbf{O}_{\mathbf{2}} \\
(\mathbf{m g} / \mathbf{l})\end{array}$ & $\begin{array}{c}\text { Decompositi } \\
\text { on of } \mathbf{H}_{2} \mathbf{O}_{2} \\
\mathbf{( \% )}\end{array}$ \\
\hline 350 & 6.8 & 116.4 & 22 \\
\hline 400 & 5.9 & 100.3 & 33 \\
\hline 450 & 5.5 & 93.5 & 37 \\
\hline 500 & 4.7 & 79.9 & 46 \\
\hline 550 & 5.1 & 86.7 & 42 \\
\hline 600 & 5.2 & 88.4 & 41 \\
\hline 650 & 4.8 & 81.6 & 45 \\
\hline 700 & 2.8 & 47.6 & 68 \\
\hline 750 & 2.5 & 42.5 & 71 \\
\hline 800 & 2.6 & 44.2 & 70 \\
\hline
\end{tabular}

The results of experiments on the decomposition of $\mathrm{H}_{2} \mathrm{O}_{2}$ on carbon-mineral materials showed that CMM can be used as a catalyst for the decomposition of hydrogen peroxide in the processes of oxidative destruction of surfactants in wastewater [5]. The degree of decomposition of $\mathrm{H}_{2} \mathrm{O}_{2}$ of the best samples was $70-71 \%$ at an initial $\mathrm{H}_{2} \mathrm{O}_{2}$ concentration of $150 \mathrm{mg} / \mathrm{l}$ and a $\mathrm{pH}$ value of 10; for activated carbon BAU under the same conditions the value of the degree of decomposition of $\mathrm{H}_{2} \mathrm{O}_{2}$ was $42 \%$ [6].

The CMM sample, pyrolyzed at $750{ }^{\circ} \mathrm{C}$, was researched in the process of destructive purification of wastewater from neonol AF9-10 in a dynamic mode. The results are presented in Table. 3 .

As a result of the experiment, the maximum oxidation state of the surfactant which was $86.4 \%$ was reached on 30 th min. The subsequent decrease in the oxidation state is apparently associated with the decomposition of hydrogen peroxide, which must be added into the solution in dosage. 
We can conclude that CMM have a sufficiently high catalytic activity and can be used for destructive purification of solutions from nonionic surfactants such as neonol AF9-10.

The conducted research allows us to conclude that adsorbents and catalysts based on CMM are promising materials for purifying wastewater from organic compounds.

Table 3. Oxidation of neonol AF9-10 with hydrogen peroxide on a CMM sample pyrolyzed at $750^{\circ} \mathrm{C}$ in a dynamic mode.

\begin{tabular}{|c|c|c|c|}
\hline $\begin{array}{c}\text { Time } \\
(\mathbf{m i n})\end{array}$ & $\begin{array}{c}\text { Residual } \\
\text { content of } \\
\text { neonol AF9-10 } \\
\text { (mg/l) }\end{array}$ & $\begin{array}{c}\text { Solution } \\
\text { volume } \\
\text { (l) }\end{array}$ & $\begin{array}{c}\text { Decompositio } \\
\text { n of neonol } \\
\text { AF9-10 (\%) }\end{array}$ \\
\hline 30 & 6.8 & 0.2 & 86.4 \\
\hline 60 & 10.2 & 0.4 & 79.7 \\
\hline 90 & 15.1 & 0.6 & 69.7 \\
\hline 120 & 17.3 & 0.8 & 65.5 \\
\hline 150 & 18.9 & 1 & 62.1 \\
\hline 180 & 16.3 & 1.2 & 67.3 \\
\hline
\end{tabular}

\section{Conclusion}

The results showed that pyrolysis of granules from a mixture of natural montmorillonite clay and tire crumbs in an airless condition leads to the production of a carbonmineral material with the properties of an adsorbent and a catalyst. Elemental analysis showed that the iron content in the pyrolyzed samples was 2.5-4.0 mass \%. Carbon deposits on the montmorillonite surface in the samples varied from 17 to 48 mass $\%$. The hydrophobization of the clay surface manifested itself in a decrease in the adsorption of water vapor by CMM samples with an increase in the pyrolysis temperature.

Example of the adsorption of neonol AF9-10 from aqueous solutions showed that in terms of adsorption activity to nonionic surfactants, the obtained CMM is slightly inferior to industrial activated carbons, but it may well be recommended for use as an adsorbent for purifying wastewater from high molecular weight organic pollutants from various industries.

It was found that with an increase in the pyrolysis temperature, an improvement in the catalytic properties of CMM samples was observed in the processes of the decomposition of $\mathrm{H}_{2} \mathrm{O}_{2}$ and the oxidation of neonol AF910 with hydrogen peroxide.

\section{Acknowledgment}

Special thanks to D. Mendeleev Centre of Collective Use at D. Mendeleev University of Chemical Technology of Russia for performed research.

\section{References}

1. X. Yang, F. Li, M. Xia, F. Luo, Y. Jiang, Investigation on the micro-structure and adsorption capacity of cellulosic biomass carbon based montmorillonite composite (Elsevier, Amsterdam 256, 2018)

2. D. Tong, C. Wu, M. Adebajo, G. Jin, W. Yu, S. Ji, C. Zhou, "Applied Clay Science Adsorption of methylene blue from aqueous solution onto porous cellulose-derived carbon/montmorillonite nanocomposites (Amsterdam: Elsevier, 161, 2018)

3. K.S. Shykhaliev, Eurasian Union of Scientists (ESU), 6, 80-81 (2016)

4. P.V. Uchanov, I.N. Kamenchuk, N. Zholdabekova, V.M. Mukhin, Chemical Industry Today, 9, 50-56 (2014)

5. M.M. Fidchenko, L.V. Omelyanenko, G.G. Otyrba, M.B. Alekhina, Collection of abstracts of the YI Russian conference with international participation "Technical chemistry. From theory to practice," (Institute of Technical Chemistry, Ural Branch of the Russian Academy of Sciences, Perm, 185, (2019)

6. A.I. Morozov, A.I. Rodionov, I.N. Kamenchuk, A.A Kurilkin, Advances in chemistry and chemical technology, (D. Mendeleev University of Chemical Technology of Russia, Moscow, 28, 2014) 